\title{
ANALISIS PERBANDINGAN KURVA HAZARD PADA KOTA BANDA ACEH DENGAN SUMBER GEMPA SESAR SEULIMEUM DAN MENGGUNAKAN BEBERAPA FUNGSI ATENUASI
}

\author{
Imam Trianggoro Saputro' ${ }^{1)}$, Muh. Akhsan Samaila ${ }^{2)}$ \\ ${ }^{1), 2)}$ Program Studi Teknik Sipil, Universitas Muhammadiyah Sorong \\ Email : Imam.civil10@gmail.com
}

\begin{abstract}
Abstrak
Kota Banda Aceh merupakan daerah yang rawan terhadap gempa bumi karena terdapat zona subduksi dan sesar di daerah tersebut. Salah satu sesar yang melewati daerah tersebut adalah sesar Seulimeum. Sesar ini membentang sepanjang $122 \mathrm{~km}$ di daratan pulau Sumatra. Ancaman gempa bumi dari sesar ini tentunya dapat membahayakan daerah sekitar. Pada penelitian ini melakukan analisis kurva hazard untuk mengetahui berapa besar percepatan tanah (ground acceleration) yang terjadi akibat gempa bumi pada wilayah ini dengan berbagai macam kala ulang (return period). Probabilitas terlampaui yang digunakan adalah 10\% dengan umur rencana 50 tahun. Kurva hazard dianalisis menggunakan fungsi atenuasi Donovan (1972), fungsi atenuasi Esteva (1972), fungsi atenuasi Cornel (1979), Campbell (1989), dan Xiang \& Gao (1994). Hasil penelitian menunjukkan besarnya nilai percepatan tanah (ground acceleration) akan meningkat seiring dengan besarnya nilai kala ulang (return period) yang diperhitungkan. Kurva hazard pada daerah Banda Aceh akibat sesar Seulimeum akan menunjukkan nilai terbesar pada saat menggunakan fungsi atenuasi Donovan (1972) sedangkan yang terkecil adalah menggunakan fungsi atenuasi Esteva (1972).
\end{abstract}

Kata Kunci : Kurva Hazard, Atenuasi, Sesar Seulimeum, Banda Aceh

\section{Pendahuluan}

Pulau Sumatra terletak di sebelah barat wilayah negara Indonesia. Resiko gempa pada wilayah ini tergolong tinggi. Hal ini disebabkan sepanjang pulau Sumatra terdapat zona subduksi yang lokasinya sejajar dengan garis pantai. Selain itu, pada daratan pulau Sumatra terdapat sesar yang terbagi kedalam beberapa segmen. Setidaknya terdapat 19 segmen pada wilayah ini. Salah satu segmen sesar yaitu seulimeum. Sesar seulimeum memiliki Panjang sekitar $122 \mathrm{~km}$ yang tentunya ini merupakan zona bahaya terhadap daerah sekitar sesar ini.

Kota banda Aceh merupakan salah satu kota yang terletak dekat dengan sesar seulimeum. Lokasi ini tentunya sangat berpotensi terhadap ancaman gempa yang bersumber pada sesar tersebut. Kejadian gempa bumi memiliki kala ulang (return period). Semakin besar kala ulang (return period) yang diperhitungkan maka resiko ancaman bahaya akan semakin besar juga.

Salah satu parameter yang diperhitungkan dalam analisis struktur gedung tahan gempa adalah percepatan tanah yang terjadi pada saat gempa bumi.
Data ini sangat penting diketahui mengingat frekuensi gempa di daerah pulau Sumatra terkhususnya kota banda aceh sangat sering terjadi.

Kurva hazard adalah suatu grafik yang menunjukkan hubungan antara percepatan tanah (ground acceleration) terhadap kala ulang (return period) dari suatu gempa bumi. Dengan menganalisis kurva ini maka dapat diperoleh nilai besaran percepatan tanah pada setiap kala ulang tertentu yang terjadi pada suatu wilayah.

Besarnya percepatan tanah tidak hanya dipengaruhi oleh magnitudo dan jarak gempa dari episenter. Namun terdapat pengaruh lain yaitu fungsi atenuasi dan kondisi setempat (local site). Pada penelitian ini mencoba menganalisis besarnya nilai kurva hazard dari beberapa fungsi atenuasi sehingga dapat mengetahui seberapa besar pengaruh yang dihasilkan.

\section{Tujuan}

Penelitian ini bertujuan untuk menganalisis kurva hazard pada daerah kota Banda Aceh terhadap sumber gempa berupa sesar seulimeum dengan memperhitungakan beberapa fungsi 
atenuasi diantaranya ; fungsi atenuasi Donovan (1972), fungsi atenuasi Esteva (1972), fungsi atenuasi Cornel (1979), Campbell (1989), dan Xiang \& Gao (1994).

\section{Metode}

Refensi dalam penelitian ini mengikuti Widodo (2012) dan Douglas (1991). Untuk urutan metode yang digunakan dalam penelitian ini adalah sebagai berikut:

a. Mengidentifikasi koordinat kota Banda Aceh dan sesar Seulimeum

b. Menganalisis jarak terdekat dari sesar Seulimeum ke Kota Banda Aceh

c. Menganalisis paremeter dan fungsi Atenuasi dari setiap persamaan.

d. Menganalisis kala ulang gempa bumi yang akan terjadi.

e. Menganalisis percepatan tanah dengan menggunakan beberapa fungsi atenuasi

f. Membuat kurva hazard hasil dari analisis.

g. Kesimpulan

\section{Analisis dan Pembahasan}

\section{Identifikasi Koordinat Lokasi}

Identifikasi koordinat lokasi dilakukan untuk mengetahui lokasi penelitian yang digunakan. Dalam penelitian ini lokasi yang dimaksud adalah kota Banda Aceh dan sesar Seulimeum. Hasil identifikasi tersaji sebagai berikut:

Koordinat Kota Banda Aceh:

Longitude : 95.05 BT

Latitude $\quad: 5.35 \mathrm{LU}$

Koordinat Sesar Seulimeum:

Bagian Ujung Utara

Longitude : 95.948 BT

Latitude : 5.001 LU

Bagian Ujung Selatan

Longitude : 95.315 BT

Latitude : $5.9 \mathrm{LU}$

Adapun lokasi penelitian dapat dilihat pada Gambar 1

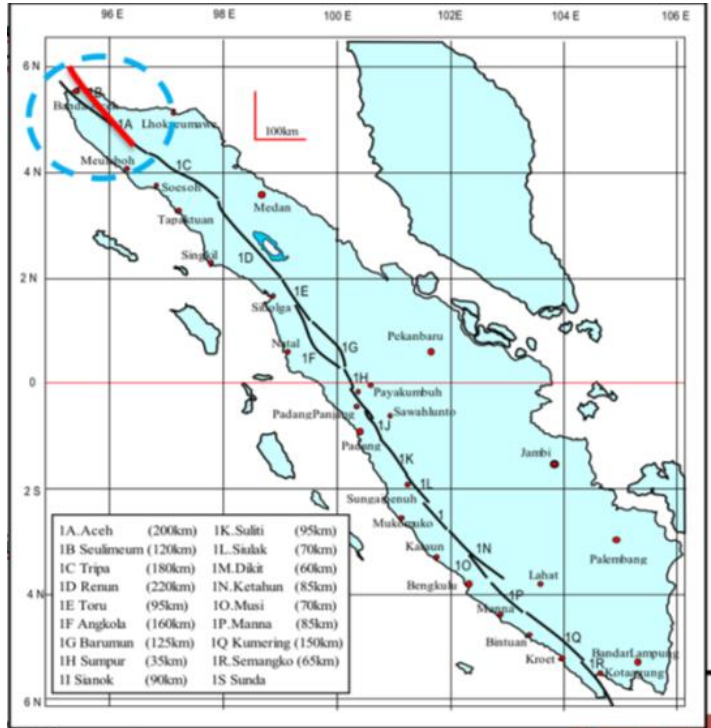

Gambar 1 Lokasi Penelitian

\section{Analisis Jarak Kota Banda Aceh Terhadap Sesar Seulimeum}

1 derajat $($ lintang/bujur $)=111.322 \mathrm{Km}$

$\mathrm{L}=\sqrt{(95.315-95.948)^{2}+(5.9-5.001)^{2}}$

$\mathrm{x} 111.322=122.398 \mathrm{~km}$

$$
\begin{aligned}
& \text { L1 }=\frac{r 1^{2}-r 2^{2}+L^{2}}{2 L} \\
& =33.078 \mathrm{~km} \\
& \text { L2 = (L-L1) } \\
& =89.320 \mathrm{~km} \\
& \mathrm{r} 1=\sqrt{(95.315-95.05)^{2}+(5.9-5.35)^{2}} \\
& \mathrm{x} 111.322=67.963 \mathrm{~km} \\
& \mathrm{r} 2= \\
& \sqrt{(95.948-95.05)^{2}+(5.001-35.35)^{2}} \\
& \mathrm{x} 111.322=107.251 \mathrm{~km} \\
& \mathrm{r}=\sqrt{r 1^{2}-L 1^{2}} \\
& =\sqrt{67.963^{2}-33.078^{2}} \\
& =59.370 \mathrm{~km}
\end{aligned}
$$




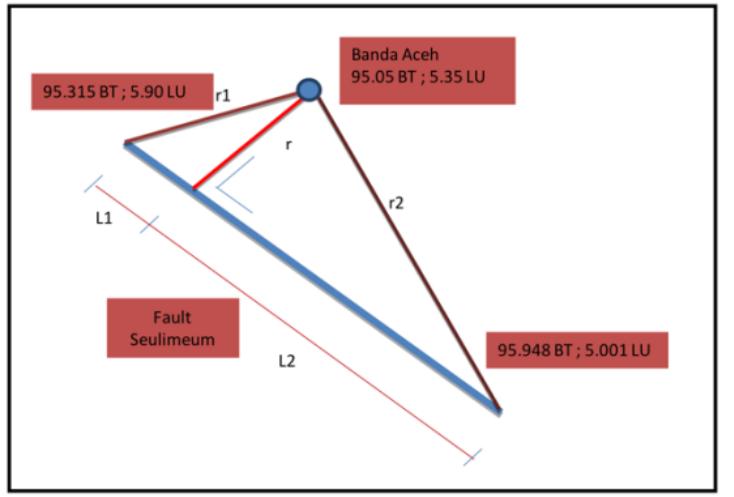

Gambar 2 Jarak Kota Banda Aceh dan Sesar Seulimeum

\section{Menghitung Fungsi Atenuasi}

Fungsi atenuasi perlu diperhitungkan karena kekuatan gempa bumi berpengaruh terhadap jarak dari episenter gempa. Semakin jauh maka kecenderungan kekuatannya menurun. Walaupun terdapat beberapa kasus yang berbeda. Tetapi hal ini disebabkan oleh kondisi setempat (local site).

Dalam penelitian ini fungsi atenuasi yang digunakan adalah fungsi atenuasi Donovan (1972), fungsi atenuasi Esteva (1972), fungsi atenuasi Cornel (1979), Campbel (1989), dan Xiang \& Gao (1994).

Fungsi Atenuasi Donovan (1972)

$$
\begin{aligned}
Y & =b_{1} e^{b_{2} \cdot M} R^{-b_{3}} \\
& =1320 . e^{0.58 \cdot M}(R+25)^{-1.52}
\end{aligned}
$$

Tabel 1 Perhitungan Fungsi Atenuasi Donovan (1972)

\begin{tabular}{ccc}
\hline Parameter & Nilai & Satuan \\
\hline Mo & 4 & (asumsi) \\
$\beta$ & 2 & (asumsi) \\
No & 0.083 & \\
b1 & 1320 & \\
b2 & 0.58 & \\
b3 & -1.52 & \\
& & \\
Nt & 9 & \\
t & 108 & \\
No & 0.083 & eq/th \\
& & eq/th/km \\
$\mathrm{N}$ & 0.00037931 & fault \\
\hline
\end{tabular}

Koeffisien C dan $\gamma$

$$
\begin{aligned}
C & =e^{\beta \cdot M_{o}} b_{1}^{\beta / b_{2}} \\
& =1.71773 \mathrm{E}+14 \\
\gamma & =\frac{\beta . b_{3}}{b_{2}} \\
& =-5.24137931
\end{aligned}
$$

Menghitung $\mathrm{f}(\mathrm{x})$

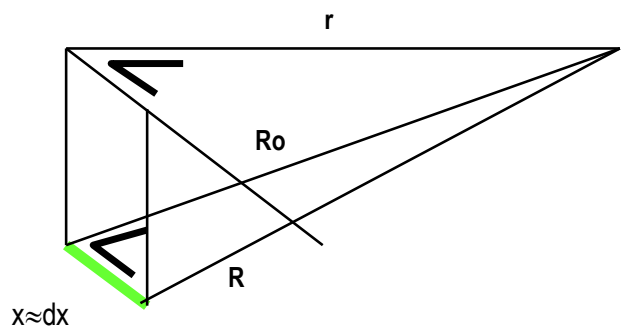

Gambar 3 Permodelan Perhitungan

$$
\begin{array}{ll}
\mathrm{f}(\mathrm{x})=\left(\sqrt{\mathrm{R}_{\mathrm{o}}^{2}+\mathrm{x}^{2}}\right. & +\Delta)^{\gamma} \\
\mathrm{r} & =59.370 \mathrm{~km} \\
\mathrm{x} 1 & =0 \\
\mathrm{dx} & =0.5 \mathrm{~km} \\
\text { Kedalaman }(\mathrm{h}) & =10 \mathrm{~km} \\
\text { Ro }=\sqrt{r^{2}+h^{2}} & =60.207 \mathrm{~km} \\
\Delta & =25 \\
\gamma & =-5.2414
\end{array}
$$

$$
\begin{aligned}
f(x o) & =\left(\sqrt{60.207^{2}+0^{2}}+25\right)^{-5.2414} \\
& =7.61471 \mathrm{E}-11
\end{aligned}
$$

$$
\begin{aligned}
f(x 1) & =\left(\sqrt{60.207^{2}+0.5^{2}}+25\right)^{-5.2414} \\
& =7.61374 \mathrm{E}-11 \text { dst. }
\end{aligned}
$$

Menghitung Luasan

$$
\text { Area }=G=\frac{\Delta x}{2}\left\{f_{o}+2 . f_{i}+f_{n}\right\}
$$

Segmen 1

$\mathrm{L} 1=33.08 \mathrm{~km}$

Segmen 2

$\mathrm{L} 2=89.31 \mathrm{~km}$ 
$\mathrm{L}=\mathrm{L} 1+\mathrm{L} 2=122.39 \mathrm{~km}$

$\mathrm{G} 1=2.16039 \mathrm{E}-09$

$\mathrm{G} 2=5.91222 \mathrm{E}-11$

$\mathrm{Gt}=2.21951 \mathrm{E}-09$

Menghitung besar kala ulang dan besarnya percepatan tanah. Dalam hal ini probabilitas terlampaui $10 \%$ dengan umur rencana 50 tahun.

$R n=1-\left[1-\frac{1}{T_{R}}\right]^{N}$

$P a=\frac{R n}{N}$

$P a=N C G \cdot Y^{-\frac{\beta}{b 2}}$
$Y=\left(\frac{N C G}{P a}\right)^{b 2 / \beta}$

Berdasarkan hasil analisis di atas maka diperoleh kurva hazard seperti yang terlihat pada Gambar 4 berikut.

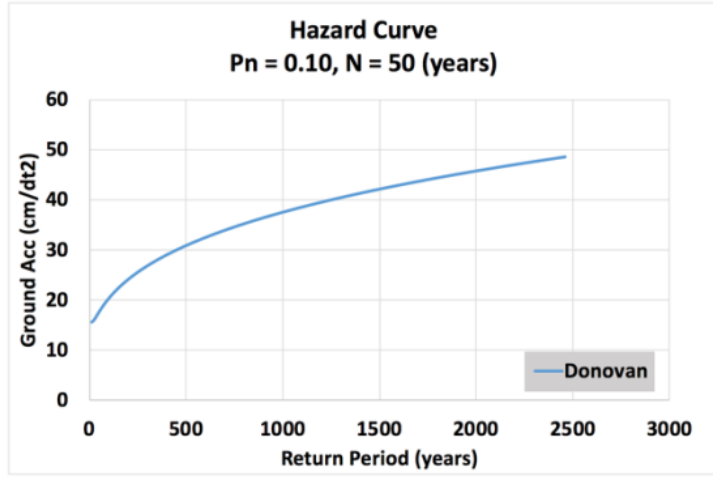

Gambar 4 Kurva Hazard dengan Atenuasi Donovan (1972)

\section{Fungsi Atenuasi Esteva (1972)}

Perhitungan dilakukan seperti fungsi atenuasi sebelumnya. Namun memenuhi fungsi persamaan berikut.

$$
Y=1230 \cdot e^{0.8 \cdot M} \cdot(R+25)^{-2}
$$

Berdasarkan persamaan tersebut maka diperoleh kurva hazard seperti yang terlihat pada Gambar 5 berikut.

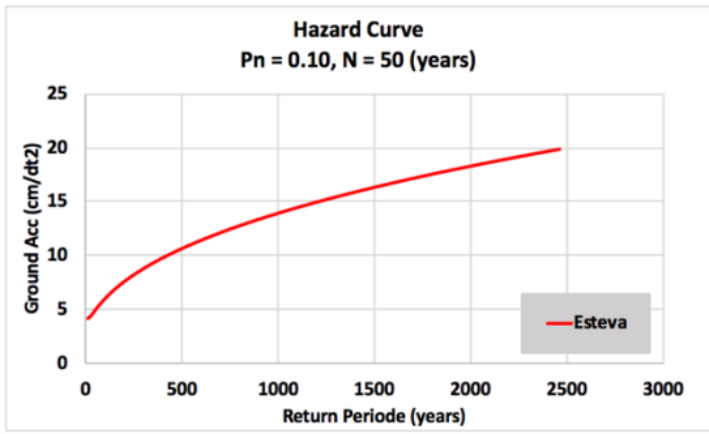

Gambar 5 Kurva Hazard dengan Atenuasi Esteva (1972)

\section{Fungsi Atenuasi Cornel (1979)}

Perhitungan dilakukan seperti fungsi atenuasi sebelumnya. Namun memenuhi fungsi persamaan berikut.

$$
\begin{aligned}
Y & =e^{6,74} \cdot e^{0,858 \cdot M_{L}} \cdot(R+25)^{-1,80} \\
& =845 \cdot e^{0,858 \cdot M_{L}} \cdot(R+25)^{-1,80}
\end{aligned}
$$

Berdasarkan persamaan tersebut maka diperoleh kurva hazard seperti yang terlihat pada Gambar 6 berikut.

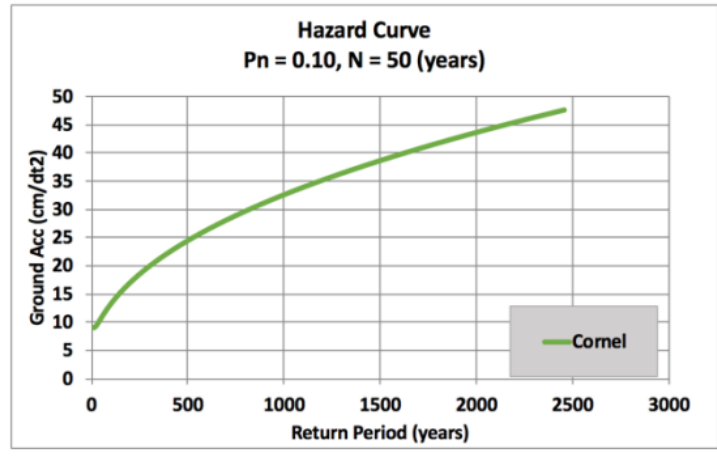

Gambar 6 Kurva Hazard dengan Atenuasi Cornel (1979)

\section{Fungsi Atenuasi Campbel (1989)}

Perhitungan dilakukan seperti fungsi atenuasi sebelumnya. Namun memenuhi fungsi persamaan berikut.

$$
Y=0,082 \cdot e^{0.623 . M_{L}} \cdot(R+7,8)^{-1,0}(g)
$$

Berdasarkan persamaan tersebut maka diperoleh kurva hazard seperti yang terlihat pada Gambar 7 berikut. 


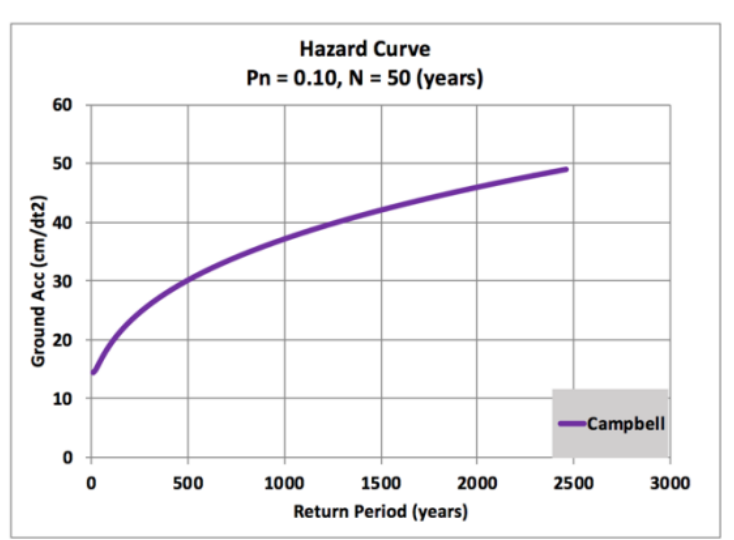

Gambar 7 Kurva Hazard dengan Atenuasi Campbell (1989)

\section{Fungsi Atenuasi Xiang \& Gao (1994)}

Perhitungan dilakukan seperti fungsi atenuasi sebelumnya. Namun memenuhi fungsi persamaan berikut.

$$
Y=1291,07 \cdot e^{0.5275 \cdot M_{L}} \cdot(R+15)^{-1,5785}(\mathrm{~cm} / \mathrm{sc} 2)
$$

Berdasarkan persamaan tersebut maka diperoleh kurva hazard seperti yang terlihat pada Gambar 8 berikut.

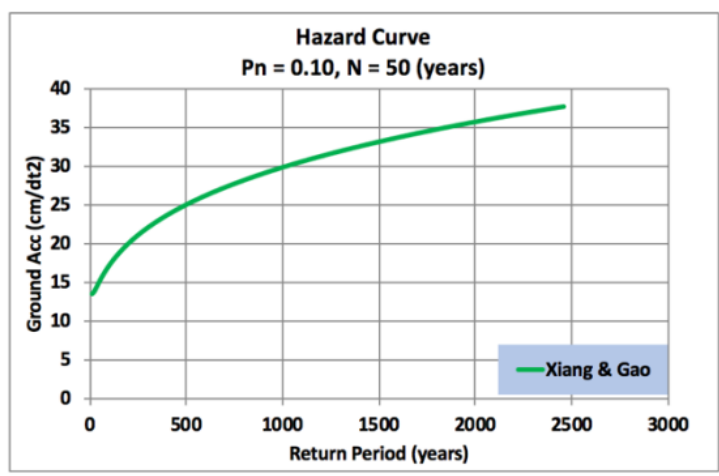

Gambar 8 Kurva Hazard dengan Atenuasi Xiang \& Gao (1989)

\section{Perbandingan Fungsi-Fungsi Atenuasi}

Setelah melakukan analisis dengan menggunakan fungsi atenuasi Donovan (1972), fungsi atenuasi Esteva (1972), fungsi atenuasi Cornel (1979), Campbell (1989), dan Xiang \& Gao (1994)di atas maka diperoleh hasil kurva hazard seperti yang tersaji pada Gambar 9 berikut ini.

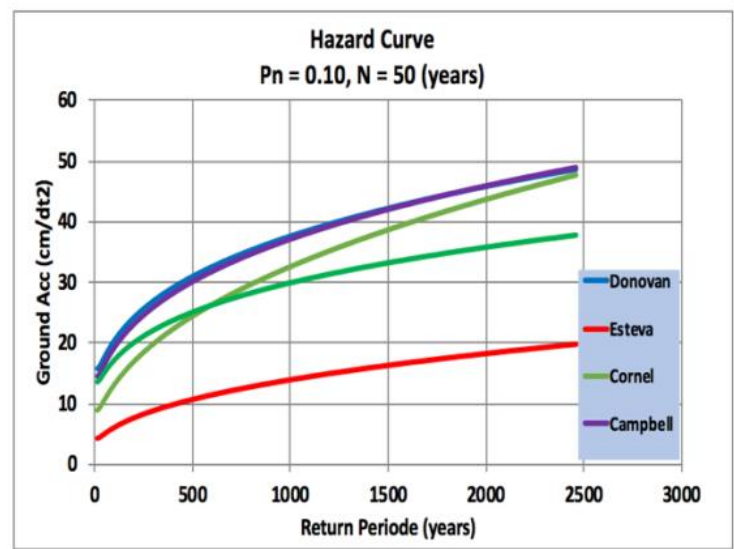

Gambar 9 Perbandingan Kurva Hazard dengan Beberapa Fungsi Atenuasi

Berdasarkan hasil Gambar 9 di atas menunjukkan besarnya nilai percepatan tanah (ground acceleration) akan meningkat seiring dengan besarnya nilai kala ulang (return period) yang diperhitungkan. Fungsi atenuasi Campbel (1989) dan fungsi atenuasi Donovan (1972) menghasilkan nilai yang hampir mirip dimana grafik yang terjadi saling bersinggungan.

Hasil penelitian juga menunjukkan bahwa kurva hazard menunjukkan nilai terbesar pada saat menggunakan fungsi atenuasi Donovan (1972) sedangkan nilai terkecil pada kurva hazard terjadi pada saat menggunakan fungsi atenuasi Esteva (1972).

Kurva hazard ini dapat digunakan dalam menentukan besarnya percepatan tanah di daerah banda aceh yang disebabkan oleh sumber gempa sesar seulimeum. Hal ini juga dapat dianggap sebagai langkah mitigasi.

Upaya mitigasi perlu dilakukan untuk mengidentifikasi bencana yang akan terjadi dikemudian hari dengan mengambil langkah antisipasi. Hal ini dilakukan dalam rangka untuk mengurangi resiko yang ditimbulkan sehingga tingkat kerugian dan korban yang berjatuhan dapat diminimalisir. 


\section{Kesimpulan}

Berdasarkan hasil penelitian maka diperoleh beberapa kesimpulan sebagai berikut ini:

1. Besarnya nilai percepatan tanah (ground acceleration) akan meningkat seiring dengan besarnya nilai kala ulang (return period) yang diperhitungkan.

2. Kurva hazard pada daerah Banda Aceh akibat sesar Seulimeum akan menunjukkan nilai terbesar pada saat menggunakan fungsi atenuasi Donovan (1972).

3. Kurva hazard pada daerah Banda Aceh akibat sesar Seulimeum akan menunjukkan nilai terkecil pada saat menggunakan fungsi atenuasi Esteva (1972).

\section{Daftar pustaka}

Campbell K. W, 1981, Near-sorce Attenuation of Peak Horizontal Acceleration, Bulletin of the Seismological society of America, Vol.71, No.6, pp.20392070

Douglas J, 1991, A Comprehensive World-wide Summary of Strong-motion Attenuation Relationships for Peak Ground Acceleration and Spectral Coordinates, Engineering Seismology and Earthquake Engineering, Civil Engineering Department, Imperial College of Science, Technology and Medicine

Widodo, 2012, Seismologi Teknik \& Rekayasa Kegempaan, Pustaka Pelajar, Yogyakarta 